\title{
Cultura e costumes: um campo em disputa
}

\author{
Culture and mores: \\ a dispute field
}

\section{Carla Reis Longhi*}

\section{RESUMO}

Este artigo propõe a reflexão sobre o âmbito cultural no contexto da ditadura militar, priorizando a reflexão sobre os costumes. Propomos a análise do discurso produzido pelos governos militares sobre o tema, presente em documentação de circulação institucional, cruzando a perspectiva aí presente com as ações políticas de fomento cultural e o discurso publicitário daí decorrente, vislumbrando um campo em disputa, constituído por uma contínua tensão entre a ação repressora e a busca de legitimação. Nesta relação dicotômica, a ditadura militar buscou disseminar seu projeto ideológico na constituição de um Estado caracterizado por um modelo de desenvolvimento ao mesmo tempo modernizador e conservador.

Palavras-chave: Ditadura Militar. Projetos culturais. Costumes. Discurso.

\section{ABSTRACT}

This article proposes a reflection about culture during the military dictatorship, prioritizing the reflection on costumes. It is proposed the analysis of speachs produced by military dictatorship governaments about the theme, that are present in institucional circulation documents, crossing the presented perspective with the political actions for cultural promotion and the publicist speach therefore present, forming a dispute field that is constituted by a continuous tension between repressives actions and the legitimation search. In this dichotomous relation, the military dictatorship tried to disseminate its idealogical project with the creation of a state, caracterized by a, at same time, modern and conservative development.

Keywords: Military Dictatorship. Cultural projects. Mores/Costumes. Speach.

\footnotetext{
* Doutora em História Social pela USP/SP e Pós-Doutora em Comunicação Social pela Facultad de Ciencias de la Información de la Universidad Complutense de Madrid. Professora Coordenadora do Curso de História da PUC/SP e na mesma instituição professora no Programa de Pós-Graduação em História.Também professora do Programa de Pós-Graduação em Comunicação da UNIP.
} 


\section{Introdução}

Os 50 anos do golpe militar propiciaram uma nova demanda de debates e discussões sobre o golpe civil- militar de 1964 e a estruturação da ditadura militar. Estes novos debates foram permeados pelo relatório da Comissão Nacional da Verdade, finalizada e entregue à Presidência da República em 10/12/2014, além das discussões presentes nas Comissões da Verdade dos âmbitos estaduais e municipais, bem como de outros fóruns. Estas comissões colaboraram com a disseminação do debate, bastante presente nas mídias em geral e com a circulação de novos documentos, aspecto este essencial para a possibilidade de novos enfoques e contínuo diálogo com a memória constituída.

Ao ponderarmos sobre a produção historiográfica, vemos como algumas grandes questões preponderavam sobre a tematização dos fatos (golpe e ditadura) que, aliadas às fontes disponíveis e métodos propostos em cada momento, definiram análises sempre historicamente dadas. Nos anos 1960-70 circulavam as ideias de revolução e desenvolvimento, associadas a definidos modelos teóricos como o modelo do Estado burocrático-autoritário, com maior evidência entre cientistas sociais; nos anos 1980 e 90 diferentes setores discutiam o caráter democrático, o papel dos diferentes atores e começavam os debates sobre a memória, tanto militar quanto da resistência, em função da gama de biografias publicadas neste período trazendo, inclusive, a reflexão metodológica sobre estes novos documentos. Vemos, agora, que este eixo da memória articula-se ao direito à verdade e a discussão sobre a responsabilização, recolocando o debate em outros termos. Muitas pesquisas ainda vêm retomando temas como o do modelo do Estado, ponderando agora sobre as especificidades da estratégia modernizante -autoritária ou o tema da cultura, central neste artigo, observando entre outros aspectos a especificidade da produção artístico-cultural ao longo da ditadura. Com o intuito de contribuir com este longo debate, propomos para este artigo a reflexão sobre a cultura, entendendo-a como um importante campo em disputa. Como bem colocado por Napolitano:

O campo da cultura foi fundamental para configurar tanto as críticas das oposições ao regime militar brasileiro (1964-1985) quanto estabelecer canais de negociação entre Estado e sociedade. Dessa maneira, a cultura e as artes daquele período incorporaram, a um só tempo, formas de resistência e formas de cooptação e colaboração, diluídas num gradiente amplo de projetos ideológicos e graus de combatividade e crítica, entre um e outro polo. (NAPOLITANO, 2011, 147)

Como indicado por Napolitano, os governos militares sempre estiveram atentos ao âmbito cultural, vislumbrando aí um importante espaço de negociações e controle. Ao 
observarmos o contexto, como discutido pelo autor, percebemos a constituição de um percurso de atuação em relação à produção cultural que foi se reformulando ao longo da ditadura. Assim, ao retomarmos o âmbito cultural notamos a circulação de diferentes e conflitantes práticas e projetos culturais, produções artísticas e vertentes discursivas. $\mathrm{O}$ autor identifica uma preponderância de projetos culturais de esquerda, reforçados no pós-68 pela ampliação da associação entre setores de esquerda e setores liberais à frente de produções midiáticas, numa composição que viabilizou uma extensa produção artísticocultural de oposição aos governos militares, configurando a prevalência de uma cultura de esquerda no período. Considerando o Estado notamos, num primeiro momento, a disseminação de práticas repressoras direcionadas ao campo artístico-cultural buscando desarticular as aproximações e vínculos destes bens e produtos aos grupos de esquerda, seguidas da censura aos produtos artísticos, tais como, a censura à letras de música, peças teatrais etc., bem como, a perseguição aos artistas, provocando um bom número de exílios neste período. Como já discutido longamente por parte da historiografia (Napolitano (2011) Ridenti (2010) e outros), a ação repressiva se direcionava aos produtos e não ao próprio campo, campo este necessário ao próprio Estado, que tentava emplacar seus projetos ideológicos, agindo, entre outras formas, na propagação de um discurso ufanista, disseminado pela propaganda nos diferentes meios e reforçando rituais em torno das principais efemérides, ${ }^{1}$ apontando para uma atuação direta institucional, principalmente a partir do pós-1968.

$\mathrm{Na}$ oposição, além dos setores artístico-culturais com claro engajamento político, até partidário, vemos a disseminação de um discurso libertário, em diferentes nichos sociais, nascido e disseminado no contexto de 1968 , próprio de práticas cotidianas, alimentando distintos setores, entre eles, o movimento feminista, muito atuante durante toda a ditadura; os movimentos homossexuais, bem como, o movimento negro. Este cenário aponta para uma tessitura sócio-cultural diversificada em seus projetos e perspectivas de ação, indicando uma multiplicidade de enfrentamentos internos, próprios de um campo que não se constitui de forma monolítica. Justamente por isso, identificamos, também, a circulação de um intenso discurso autoritário e/ou conservador presente, entre outros, em estratos sociais herdeiros da 'Marcha da Família com Deus pela Liberdade', formados por associações femininas católicas, apoiados por discursos políticos, preocupados com a moral e os costumes. Por fim, considerando o âmbito do mercado, temos um discurso desenvolvimentista-modernizador, alimentado pela indústria cultural, entranhando-se na produção artística, no discurso ufanista e nas práticas cotidianas através da força da publicidade e da proliferação das diferentes mídias, no incentivo ao consumo. São diferentes vertentes, criando uma rica e complexa tessitura de análise.

\footnotetext{
${ }^{1}$ Esta conduta foi específica do governo de Garrastazu Médici, através da vasta produção da AERP a partir de 1970. Carlos Fico, em sua Tese 'Reinventando o Otimismo: ditadura, propaganda e imaginário social no Brasil (1969-1977)' discute amplamente a organização da AERP depois ARP ao longo dos governos militares.
} 
Para este artigo centralizar-nos-emos na análise das estratégias e práticas do Estado, articulando dois campos entre os vários indicados: sua produção discursiva sobre a cultura, presente na documentação de comunicação SNI-DEOPS/SP e sua relação com o mercado, através da produção discursiva do mercado a partir da publicidade, considerando-se o contexto da lógica da indústria cultural, que no caso brasileiro, foi fomentada pelo próprio Estado. Nossa intenção é a de reconstituir as estratégias e ações do Estado, processadas na dicotomia repressão versus legitimidade.

\section{Repressão e Legitimidade}

Nossa pesquisa centraliza-se no período a partir de 1969, pois ali se articularam importantes e distintas estratégias de Estado. Comecemos com um mapeamento das práticas políticas repressoras dos governos militares no pós-1968. Este foi o período que ficou conhecido como 'os anos de chumbo' ou do 'golpe dentro do golpe' em função da estruturação do aparato propriamente repressivo e sua consequente repressão social através de seus dois grandes pilares: a tortura e a censura. Não propomos a reflexão sobre estas denominações, mas entendemos que carregam interpretações arriscadas, como o entendimento de que houve uma mudança de curso, com predomínio de setores radicais - a nosso ver, a intensificação das estratégias de repressão demonstra a dificuldade em se estabelecer a legitimidade esperada.

Retomemos rapidamente as mudanças mais visíveis processadas no aparato repressivo do Estado a partir de 1969. Começamos com as mudanças na forma de se constituir a informação, considerando o aparato informativo como parte do aparato repressivo analisado. Ao observarmos a documentação de comunicação entre o SNI (Serviço Nacional de Informação, 1964) e o DEOPS/SP (Departamento Estadual da Ordem Política e Social) percebemos que até setembro de 1969 toda a comunicação estava centrada na produção e difusão de informação com origem no DEOPS/SP direcionada ao SNI - Agência São Paulo. A partir deste mês o maior montante da documentação arquivada nas pastas de comunicação SNI-DEOPS/SP passa a ser produzida pelo SNI e difundida para os diferentes órgãos do aparato repressivo. O primeiro tipo documental produzido neste momento chamava-se 'Boletim Informativo' (BI) e circulou de setembro de 1969 até junho de 1970, sendo substituído por um outro tipo documental denominado 'Apostila do Comunismo Internacional' (CI), predominante entre junho de 1970 até setembro de 1973. Isto indica uma clara alteração na tipologia documental, nos órgãos produtores e principalmente na intencionalidade de sua produção demonstrando o interesse, por parte do SNI, de produzir discurso. Segundo Foucault “...o discurso não é simplesmente aquilo que traduz as lutas ou os sistemas de dominação, mas aquilo por que, pelo que se luta, o poder do qual nos queremos apoderar" (FOUCAULT, 2010, p.10), o que demonstra, por sua vez, a necessidade de disputa e controle do poder na forma de discurso. Ao observarmos o conteúdo dos $\mathrm{BI}(\mathrm{s})$, 
constatamos a organização em mosaico, através de coletânea de extratos da informação jornalística, o que confirma a afirmação de Fico que "As informações serviam para manter os diversos órgãos integrantes da comunidade em constante comunicação, numa atividade que tinha muito de autoconvencimento por retroalimentação"(FICO, 2001, p. 83). A retroalimentação e autoconvencimento visavam alimentar a comunicação interna com conteúdo linear e contínuo, reforçando ideias e conceitos de modo simplificado.

Ao mesmo tempo, temos a estruturação do aparato repressivo, com a organização dos DOI-CODIs. Os CODIs (Centro de Operações de Defesa Interna) e os DOIs (Destacamentos de Operações de Informações), criados em 1970, eram órgãos com função operacional e, de certa forma sua criação se justifica, pois o SNI e todo seu emaranhado de setores eram estruturados para a organização e transmissão da informação e não para a operacionalização da ação frente a informação recebida. Como colocado por Adyr Fiúza:

O SNI não tinha uma seção de operações, jamais operou, jamais efetuou qualquer prisão. Penetrações em edifícios para capturar documentos, escuta telefônica, censura postal, isso ele tinha. Mas operação contra terrorismo e operação de combate não era da sua alçada. O SNI nunca se meteu. Se tomasse conhecimento, passaria para o órgão correspondente. É bom frisar que o SNI jamais prendeu, processou ou interrogou alguém. (FIÚZA apud D'ARAUJO, 1994, p. 45).

Assim, os CODIs eram responsáveis pelo planejamento, organização e execução de ações de defesa interna, tendo os DOIs como seu destacamento de ação, já que este tinha que ser acoplado a uma outra unidade fixa para lhe dar apoio logístico:

O DOI é um Destacamento de Operação de Informações. Por que destacamento? Porque no Exército temos certos termos estereotipados para certos vultos. (...) Quando não existe essa estrutura detalhada, que nós chamamos de estrutura de 'quadros de organização e efetivos', chama-se 'destacamento', que é um corpo que não tem uma estrutura e organização fixas: varia de tamanho e de estrutura de acordo com a necessidade (D'ARAUJO, 1994, p.51).

Como percebido, a função do DOI era ser uma unidade mutável, ágil, que estivesse preparada para enfrentar o inimigo e, dado o caráter difuso deste inimigo, o regime deveria conseguir ser tão ágil quanto estes na resposta a estas mutações. Em função deste entrelaçamento de ações ficaram conhecidos como DOI_CODIs. Ambos, aos moldes da OBAN (Operação Bandeirantes, julho de 1969 ), eram compostos por representantes das três forças armadas, além de membros das polícias federal civil e militar dos Estados. Vemos que são órgãos que não representavam os interesses específicos de um setor e sua composição garantia o atendimento dos interesses políticos dos governos. Justificou-se, então, sua organização pela necessidade da integração seja regional, seja das forças existentes, além de estruturar um poder que não precisava responder à burocracia já existente, apesar de passar a existir formalmente, diferentemente da OBAN, que deixa de existir. Um último 
órgão do sistema repressivo precisa ser comentado: é o SISSEGIN (Sistema de Segurança Interna no País); é o equivalente ao SISNI no aparato de segurança. Colocado em prática em janeiro de 1970, pôde ser constituído calcado na certeza da suspensão de algumas garantias individuais, como o habeas corpus, imposto pelo AI-5 e a existência do foro especial para crimes políticos, definido inicialmente pelo AI-2 e confirmado pela legislação de 1967; estas duas circunstâncias garantiam a efetivação das prisões realizadas nos princípios da Doutrina de Segurança Nacional.

O caráter repressivo do Estado se consumou desde seu início através das alterações das leis, com a imediata publicação do AI-1, e, entre outros aspectos, com a estruturação dos IPMs (Inquérito Policial Militar), que viabilizavam as prisões, cassações e exonerações. Os dados do relatório da Comissão da Verdade, abaixo indicados, nos dão a dimensão destes números, considerando-se exclusivamente às perseguições aos militares:

\footnotetext{
O atual diagnóstico da CNV revela, conforme registrado, um expressivo número de militares perseguidos, o qual pode ainda ser ampliado por novas investigações. Constata-se, por esse diagnóstico, um total de 6.591 militares perseguidos (do Exército, Marinha, Aeronáutica e Forças Policiais), incluindo nomes de oficiais e praças, bem como de policiais e bombeiros, atingidos nos anos 1980 (Comissão da Verdade - Relatório, vol. II, Textos Temáticos, p. 13).
}

O aprimoramento do aparato repressivo ocorreu em continuidade ao caráter autoritário já implantado e se moldou na dicotomia contínua entre repressão e estratégias de legitimação. Assim, no mesmo momento em que o aparato repressivo foi intensificado, como visto acima, presenciamos o fomento à propaganda através da intensificação das atividades da agência especial AERP (Agência Especial de Relações Públicas, criada em 15/01/1968), difundindo larga produção publicitária e fílmica de caráter ufanista; a mídia impressa foi recheada de propaganda governamental anunciando as grandes obras e acompanhada de frases ufanistas, algumas célebres: 'Brasil: ame-o ou deixe-o!', ou ainda, ' $O$ Brasil é feito por nós!' e 'Este é um país que vai pra frente!'. Mantendo-nos, ainda, no campo institucional, retomamos a tipologia documental iniciada em 1969, ponderando agora sobre a estruturação do discurso ali proposto, entendido por nós, como uma tentativa de legitimação, através da disseminação de sua doutrina. Como já apontado, houve um reordenamento da produção e circulação documental no interior do aparato informativo, aparecendo a partir de 1970 as 'Apostilas sobre o Comunismo Internacional', tipologia documental observada em seus aspectos formais e em seu conteúdo. Isto porque, diferentemente dos $\mathrm{BI}(\mathrm{s})$ este tipo documental agrega visivelmente a preocupação ideológica-discursiva, explicitando claramente um projeto ideológico. Ao observarmos os aspectos formais, considerando que '...é fundamental lembrar que nenhum texto existe fora do suporte que lhe confere legibilidade; qualquer compreensão de um texto, não importa de que tipo, depende das formas com as quais ele chega ao leitor' (CHARTIER, 2001, p. 220). 
Desse modo, chama-nos a atenção seu grande volume, tendo só o índice uma média de onze páginas, numa radiografia do comunismo no mundo, como observado pelo sumário sintetizado abaixo transcrito:

\section{ÍNDICE - ASSUNTO}

\section{Assuntos Gerais}

a) Racismo e 'sexismo', temas da propaganda vermelha _ a Teoria Classista de Marx e a sua falsidade. (...)

d) Dois Estados alemães anunciam entendimentos para estabelecimento de relações diplomáticas _ ingresso na ONU, o estágio seguinte.

2. Movimento Religioso

a) Na Argentina (3 sub-itens)( ${ }^{2}$ )

b) Na Bolívia (3 sub-itens)

c) No Brasil (5 sub-itens)

d) No Chile (3 sub-itens)

e) Em Cuba (sem sub-itens)

f) Na Itália (idem)

g) No Paraguai (idem)

h) No Peru (idem)

i) Na URSS (idem)

j) No Uruguai (idem)

k) No Vaticano (2 sub-itens)

3. Potências Comunistas

a) URSS (9 sub-itens)

b) URSS X China ( 3 sub-itens)

c) China (6 sub-itens)

4. Ásia e África ( 9 países)

5. Europa Oriental ( 5 países)

6.Europa Ocidental ( 7 países)

7.América do Norte ( 4 itens sobre os E.U.A)

8. América Central ( 5 itens sobre Cuba)

9. América Latina

a)Assuntos Gerais (2 sub-itens)

b)Guerrilha, Terrorismo e Subversão (5 países)

10. América do Sul ( 7 países)

11. As Organizações de Frente Comunistas (Negrito nosso ) ( 7 subitens) (3)

Alguns traços do sumário são marcantes e contínuos e nos interessam por demonstrar o aprofundamento e enfoque sobre o tema. O primeiro é o da associação entre comunismo e religião, no acompanhamento das práticas religiosas em distintos países, prioritariamente aqueles considerados sob influência comunista. No entendimento dos governos militares, as

\footnotetext{
${ }^{2} \mathrm{O}$ que estou chamando de sub-item equivale aos assuntos tratados sobre a religião/região em cada país. Estes assuntos são variáveis, inviabilizando a transcrição completa. Neste caso, tomando a Argentina como exemplo, temos:

$1^{\circ}$. item - trata sobre a 'expectativa de ação conciliatória na crise da igreja na Argentina'; $2^{\circ}$.item - discute o perigo do crescimento do marxismo no seio da Igreja. $3^{\circ}$. item- apresenta o documento da $25^{a}$. Assembleia Plenária dos Bispos argentinos na busca de harmonizar as posições progressista e conservadora entre os clérigos.

${ }^{3}$ Pasta 20.C.043 - 032. sem número.
} 
congregações orientadas pela Teologia da Libertação estavam enquadradas nesta perspectiva e devemos lembrar que tinham uma forte atuação no Brasil, principalmente através dos Dominicanos. O segundo elemento é o fôlego do mapeamento impetrado a todo o globo, trazendo informações de todos os continentes priorizando, em cada volume, países específicos. Ainda considerando os aspectos formais das estratégias discursivas, notamos a escolha da fala de uma terceira pessoa, sempre com perfil de fala autorizada. Foucault (2010). nos lembra que todo discurso é definido por sujeitos e lugares da fala, ou seja, podemos observar nas práticas discursivas os agentes autorizados da fala e as formas de interdições que também passam pelo controle dos espaços das mesmas. No caso da apostila sobre o comunismo o sujeito da fala é sempre um órgão (um governo, um jornal, um livro) ou um representante oficial (um político ou uma pessoa competente em sua área, como um médico) com fala autorizada pela figura do especialista. Os textos são longos e analíticos.

Através destes podemos perceber, de diferentes maneiras, tanto expressões do pensamento militar, como posicionamentos explícitos destes ao longo da documentação mas, principalmente, percebemos a extrema necessidade de legitimação no campo simbólico, buscada através do reforço contínuo do risco do inimigo interno. O comunismo se estrutura como o grande inimigo desde os anos de 1920, inimigo este amplamente justificado em 1964. A novidade agora, para além do comunismo como ideologia política e projeto econômico, é a de sua associação ao campo da cultura, articulando comunismo e moralidade.

Em linhas gerais, percebemos três modalidades de estratégias discursivas no trato do tema comunismo, presente nestas apostilas. A primeira modalidade é a contínua discussão conceitual, centrada nos conceitos de liberdade, democracia, nacionalismo, ditadura, comunismo e socialismo, o que reforça a articulação comunismo-política. Estes conceitos permeiam toda a produção sobre o comunismo internacional, ora aparecendo subliminarmente através das discussões sobre o comunismo, ora através de uma discussão específica sobre cada um deles. A partir destes conceitos, que são os ideários que sustentam todos os outros títulos, percebemos os recursos utilizados pela apostila para denegrir o pensamento e a ação comunista, a prática político-econômica. Duas estruturas complementares (modalidades) são utilizadas: desmascarar o comunismo, demonstrando a enorme distância existente entre o que é propagado e o que efetivamente é realizado; neste caso, então, disponibilizam o que entendem como o pensamento proposto e a prática efetivada. A segunda forma apresenta os métodos considerados perniciosos da ação comunista para incorporar mais membros; a construção discursiva sobre estes temas frisa continuamente o caráter manipulador daqueles que utilizam estes recursos. Priorizaremos, neste artigo, a discussão sobre a terceira modalidade, vinculada diretamente aos costumes e práticas culturais. 


\section{Comunismo e cultura: alinhavando pelos costumes}

Diferentemente do que foi discutido no início do texto, ao citarmos Napolitano (2011), onde se vislumbrava uma prática repressora direcionada aos produtos culturais e artistas, vemos aqui, a tentativa de se atuar sobre o campo cultural em sua totalidade ao associar a infiltração comunista ao campo da atuação artístico-cultural. Esta conduta não é contraposta à anterior mas, sim, um desdobramento das práticas de Estado. Desse modo, por um lado, temos a repressão a agentes e produtos, por outro lado, temos uma ação mais propositiva. Esta se desdobrou em duas vertentes: a primeira, discutida pelo autor citado, que propunha estratégias de cooptação de setores e sujeitos, através de políticas públicas de fomento cultural. A segunda que aponta para estratégias de disseminação de ideários políticoculturais, numa tentativa de construção de uma perspectiva hegemônica. Objetivamos destrinchar as lógicas e conteúdos deste projeto ideológico; notamos que a estratégia central inicial foi a de retomar a ideia do inimigo comum, já historicamente dada, intensificando-a em sua associação às práticas cotidianas. Assim, o campo dos costumes é acionado como um campo de risco, fomentando uma interlocução com determinados setores da sociedade, ao abordar e compactuar com valores conservadores.

Ao observarmos, a tipologia documental "Apostilas do Comunismo Internacional" predominantemente circulante entre 1970-1974, vemos que os militares procuraram desestabilizar os produtos culturais circulantes associando-os ao inimigo interno já estabelecido. Assim, numa mesma estratégia, buscavam desmontar a lógica cultural predominante, centrada nos projetos de esquerda, desacreditando-os e inseriam como projeto cultural próprio, a intensa preocupação com a conduta moral. Sugerindo a disseminação da 'obscenidade', do amor-livre, do divórcio fácil, apelavam para o risco posto à família, em seu modelo tradicional, instituição esta central para a permanência e disseminação de um pensamento autoritário-conservador. Tomando as estratégias discursivas, os textos buscam indicar um procedimento metodológico comunista estruturado na manipulação e na mentira. Ao tratar da moral e costumes viabilizam a crítica à ala esquerda da Igreja Católica, nomeando os inimigos declarados. Dois temas são contínuos: a discussão sobre o poder dos tóxicos para a subversão dos costumes e as estratégias de propaganda subliminar presentes em todos os veículos reconhecidos: teatro, cinema, rádio e todo tipo de mídia impressa.

Vejamos o exemplo abaixo, presente no volume de setembro de 1970. Um dos temas propostos em seu 'Assuntos Gerais' traz o seguinte título: "Subversão dos Costumes Comunismo e Toxicomania"4:

${ }^{4}$ IDEM- 021, CI 09/70 
Uma das armas mais sutis e sinistras do comunismo consiste em sua persistente atividade de corromper os costumes para debilitar o mundo democrático.

A maior parte da produção de ópio e seus derivados é originária da China, e através de inúmeros canais clandestinos esparrama-se pelo mundo, produzindo lucros fabulosos e causando a desagregação das sociedades não comunistas.

Um mundo dissoluto, entregue a drogas estupefacientes e alucinantes, não possui energia e integridade moral, indispensáveis para enfrentar a ameaça comunista.

É oportuno pois relembrarmos o que ficou estabelecido no item ' $\mathrm{f}$ ' das resoluções secretas da $1^{\text {a }}$. Conferência Tricontinental realizada em 1966 em Havana. Dizia o item mencionado:

- Apoiar resolutamente a campanha a favor das drogas, baseando-a no princípio do respeito aos direitos individuais.

- manter completamente separados os quadros do partido dos canais do tráfico de narcóticos, de maneira que essa fonte de receita não possa ser vinculada a ação revolucionária; entretanto devemos combinar a insuflação do medo à guerra atômica, com o pacifismo e com a desmoralização da juventude através do estímulo ao uso de alucinógenos.

(El País, Montevidéu, 11/04/66)

Neste caso, o discurso procura tornar-se qualificado através da expressão de um respeitável jornal de outro país. Este percurso vem intensificado pela citação à fala dos próprios comunistas. Assim, mais uma vez, a estrutura discursiva procura se sustentar na fala qualificada e na apresentação dos fatos, normalmente inquestionáveis. Quanto ao conteúdo, constrói-se a ideia da existência de um projeto de degradação moral do ocidente, com o intuito de fragilizar para controlar. Através deste vemos a definição de conceitos importantes como liberdade e democracia. No caso da liberdade, seguindo uma tradição já construída durante o Estado Novo, vemos a prevalência da ideia do coletivo frente às liberdades individuais, numa clara oposição ao liberalismo e consequentemente na defesa de um Estado autoritário, que coloca a segurança acima dos direitos. Esta construção discursiva aparece em muitos textos deste tipo documental. No caso acima transcrito, alia-se degradação à disseminação proposital das drogas. Podemos observar em outro trecho documental da mesma pasta a reafirmação da condenação da droga “... ele não condena, propriamente, o uso dos tóxicos, como seria lícito esperar-se...", aliada, justamente por não condenar, à desqualificação do expositor "Essas palavras, aliadas ao que dele se conhece permite que não nos detenhamos em maiores comentários".

Ainda, nesta apostila, havia uma longa entrevista com médicos que explicaram os efeitos de várias drogas no organismo humano; tratava-se de um vasto trabalho, com 3 e $1 / 2$ páginas, diferenciando as características, efeitos e consequências de drogas, tais como, maconha, haxixe, LSD etc., acompanhada de uma tabela comparativa das drogas mais utilizadas, através dos tópicos: Tipo da droga/ Absorção/ Duração/ Efeitos/ Conseqüências. A linha vertical apresentava uma vasta tipologia de drogas: Álcool/ Fumo/ Café/ Éter/ Haxixe/ 
Tranqüilizantes/ Barbitúricos/ Anfetaminas/ Psylocibina/ LSD/ Ópio/ Morfina/ Heroína/ Codeína/ Analgésico e Cocaína. Esta discriminação das drogas indica o intuito de amplo conhecimento sobre o tema, por parte de nossas autoridades e de demonstração de amplo conhecimento científico, o que reforçaria a ampla capacidade em responder à altura, no controle do risco. Do mesmo modo que notamos que o discurso anticomunista vinha sendo construído a partir de uma fala qualificada, de alguém exterior à instituição militar e pela apresentação de fatos, percebemos também, o percurso discursivo de se destruir o autor de qualquer fala favorável ao comunismo; esta destruição, normalmente, era definida pela desqualificação do autor e, a mais forte desqualificação é a moral.

(1) Nada do que os comunistas façam está desvinculado da ideologia. Assim, esportes, cultura, arte, tudo serve de meio para propagar a mensagem comunista. A imprensa, o rádio, a literatura, a pintura, a música, o cinema, o teatro, são poderosas armas ideológicas de nosso partido ( Kruschev).

(2) Entre eles, certamente, a 'Nouvelle Vague' francesa e o 'Cinema Novo' do Brasil e toda a pletora de obras pornográficas e de contestação que invadem a cinematografia mundial, numa surda e continuada tentativa de, através da imagem fartamente difundida, destruir os valores morais do povo. ${ }^{5}$

No entender da apostila, além das drogas, todo indivíduo estava suscetível à manipulação comunista por estar exposto às atividades culturais. Os trechos ora transcritos indicam a presença da ação dos agentes comunistas em todas as áreas da comunicação, assim, a imprensa (impressa e falada), as artes de forma geral (pintura, literatura, música) estavam contaminadas ou sofriam o risco de contágio da infiltração comunista. $O$ trecho a seguir apresenta o papel da música nesta disseminação:
A música como veículo de subversão
O jornal comunista peruano 'Unidad' publicou artigo sobre a 'canção revolucionária', afirmando o seguinte: a canção revolucionária deve buscar a comunicação humana direta, nas fábricas, no campo, nas minas, junto aos pescadores, nos colégios, nas universidades e nas ruas. Deverá ser como o vento: 'onde lhe abrem a porta, deverá entrar'.
A música é um excepcional e poderoso instrumento de mobilização de opinião pública em torno de um sentimento nacional.
Ultimamente tem sido observado, no Brasil, o lançamento de canções, de populares compositores, as quais, incontestavelmente, reproduzem uma inteligente pregação ideológica. ${ }^{6}$

A música, diferente do cinema, pode chegar a qualquer ponto e, diferentemente da mídia impressa, tem um custo muito menor, tornando-se viável para todos os grupos sociais; assim, nesta leitura, seu poder de infiltração tornava-se inquestionável e o texto

\footnotetext{
${ }^{5}$ PASTA 20.c.043-26 ${ }^{\text {A }}$, doc. 3144 , CI 06/71.

${ }^{6}$ Pasta 20.C.043- 046, CI05/71, Assuntos Gerais.
} 
procurou demonstrar, também, seu poder de sedução. $O$ trecho abaixo dá amplo destaque ao risco imposto ao cinema:

Assuntos Gerais

a) O Cinema como arma psicológica dos comunistas - A minagem das resistências morais do ocidente - Festivais de cinema: instrumentos dos PCs - a necessidade de censura e do destemor em aplica-la.

O cinema é a mais importante de todas as artes.

Desmoraliza-se a mocidade de um país e a revolução comunista estará vitoriosa . ( Lenine)

Da revista 'A Defesa Nacional', de n. 632, de julho/ agosto de 1970.

O cinema é Arte; mas Arte que se tornou poderosa indústria. A esta característica deve ser somada uma outra, muito mais importante: a de arma sutil, mas eficientíssima, usada em nossos dias para subjugação da mente humana. (...)

A continuidade do documento apresenta a repetida estrutura textual, baseada na fala de uma autoridade no assunto. Mais uma vez a crítica é construída a partir de um comentário de um artigo ou trecho de livro publicado.

Vejamos o que nos diz Siegfried Kracauer no seu artigo "O espectador"(...) Os filmes, portanto, tendem a enfraquecer o consciente do espectador. O seu retraimento pode ser aumentado pela escuridão das salas de projeção. A escuridão reduz automaticamente os nossos contatos com a realidade, privando-nos da percepção de muitos elementos de informação sobre o ambiente que nos rodeia, necessários a um julgamento adequado e outras atividades mentais. Amolece a mente.

O freqüentador de cinema está mais ou menos na situação de uma pessoa que foi hipnotizada. (...) ele não pode deixar de sucumbir às sugestões que invadem o vazio de sua mente. O cinema constitui um incomparável instrumento de propaganda. Daí a declaração de Lenine: 'o cinema é para nós o mais importante instrumento de todas as artes'(...) Mas, lamentavelmente, o cinema vem sendo empregado conscientemente na dissolução dos costumes tradicionais do mundo democrático livre.

E o que estamos vendo hoje nas democracias do Ocidente?

Presenciamos o afrouxamento das idéias religiosas, dos princípios morais, dos vínculos de família, através de filmes e peças teatrais, oriundos da literatura perniciosa. Tudo isto levando a um objetivo calculado e frio: a deteriorização de todos os valores humanos, enfim a putrefação social de um país. (...)

Como pôde acontecer isso?

A explicação ultrapassa os limites deste trabalho, mas pode ser resumida nisto: os adeptos de Marx vêem armas ou meios de ataque onde outros povos vêem apenas instrumentos de relação pacífica entre os homens. (...) 


\begin{abstract}
Assim, uma Nação soberana pode ser solapada e até destruída por ações subterrâneas - tipo cavalo de Tróia - e que não podem ser caracterizados diante das leis tradicionais como atos de agressão. Povo e território agredidos por processos invisíveis acabam por render-se à vontade do Estado agressor, sem que este possa ser incriminado com provas positivas.

É missão, pois do Estado velar cuidadosamente pela defesa dos alicerces fundamentais em que repousa a consciência Nacional, combatendo por todos os meios os pontos de infiltração sutil, o trabalho demolidor que, dificilmente, poderiam ser hoje caracterizados como atos de agressão, embora na realidade sejam perigosas armas de destruição subterrâneas dos Estados. (...)

E quando intelectuais vierem a público declarar que o 'cinema novo' no Brasil está sofrendo cerceamento de sua liberdade criadora, reforçando o seu ardiloso argumento que o nosso país vem conquistando ultimamente prêmios internacionais, é preciso tapar-lhes a boca com a verdade, infelizmente muito pouco conhecida:

A maioria dos festivais, (ou quem sabe, a totalidade) que se realizam por esse mundo afora (Europa principalmente), estão sob disfarçado, mas rigoroso controle dos comunistas". ${ }^{7}$
\end{abstract}

A degradação moral é apresentada como um projeto minucioso e extenso que atua em vários setores da sociedade, em todos os países do mundo. Essencialmente procura atingir as pessoas de forma que diluam a sua capacidade crítica, através das drogas e, de modo imperceptível, através da cultura. Os últimos documentos transcritos procuraram mostrar as teias de ação comunista disseminada pela sociedade, chegando ao cidadão comum pelas revistas, jornais, cinema, televisão, música. Há o reforço contínuo à necessidade de proteção e valorização da Nação, mais uma vez retomando uma lógica discursiva autoritária em que, acima de direitos e indivíduos está a necessidade de defesa da Nação, condicionando a liberdade individual ou os direitos civis e políticos à segurança nacional. A novidade neste discurso é a associação do risco às práticas cotidianas. Esta degradação se constitui através de uma disseminação difusa. Esta estaria presente em toda ação cultural, interferindo nos valores da sociedade, visando sua completa degradação para futuro domínio. A ideia de 'disseminação difusa' associa-se à de 'coexistência pacífica' aspecto este discutido longamente dentro da própria apostila. O Comunismo difuso apresenta-se como um projeto de disseminação social, interferindo na prática cultural cotidiana e mostra-se como um projeto de longo prazo e associa-se à ideia da coexistência pacífica, como o lado de uma moeda, ou seja, só se pode pensar em estratégias de boa política internacional, por haver um projeto de inserção cultural. "Para os comunistas, a 'Coexistência pacífica' é, na verdade, uma eficiente técnica de luta de classes, e somente a contra- ofensiva apropriada e um tempo poderá impedir que seja coroada pela vitória comunista". ${ }^{8}$

A ideia de degradação moral interna (comunismo difuso), fruto de uma política externa ardilosa (na argumentação dos militares), anunciada nos termos da 'coexistência pacífica', viria de encontro à concepção de guerra interna, já consumada na legislação de 1967. Afinal,

${ }^{7}$ IDEM -030,doc. 3547, CI n. 9/71.

${ }^{8}$ IDEM- 034, doc. 3725, CI 07/72 
se o comunismo se alastra por todos os âmbitos da sociedade, atingindo as pessoas nos momentos de seu lazer, quando podem 'baixar a guarda', precisa ser controlado, pelo acompanhamento constante de todos os passos de todos os setores da sociedade, justificando a guerra revolucionária. Veja o que Maria Helena Moreira Alves coloca:

\begin{abstract}
Com o advento da guerra fria, elementos da teoria da guerra total e do confronto inevitável das duas superpotências incorporaram-se à ideologia da segurança nacional na América Latina. A forma específica por ela assumida na região enfatizava a 'segurança interna' em face da ameaça de 'ação indireta' do comunismo. Desse modo, enquanto os teóricos americanos da segurança nacional privilegiavam o conceito de guerra total e a estratégia nuclear, e os franceses, já envolvidos na guerra da Argélia, concentravam suas atenções na guerra limitada como resposta à ameaça comunista, os latino- americanos, preocupados com o crescimento de movimentos sociais da classe trabalhadora, enfatizaram a ameaça de subversão interna e da guerra revolucionária. (...) Guerra Revolucionária: conflito, normalmente interno, estimulado ou auxiliado do exterior, inspirado geralmente em uma ideologia, e que visa à conquista do poder pelo controle progressivo da nação (ALVES, 1989, p. 33-34).
\end{abstract}

Retomando nossa proposição inicial, sobre a reformulação na produção da informação, alterando a prática do SNI, acreditamos que a documentação ora analisada nos ajuda a moldar mais um sentido ou um novo sentido, para este órgão. A nosso ver, o discurso construído sobre o comunismo nas apostilas sobre o comunismo internacional cumpre um papel, por um lado, justificador e homogeneizador do discurso autoritário, logo, da repressão e, por outro lado, um discurso legitimador de um pensamento conservador. Homogeneizador, pois sabemos que não havia unidade ideológica nem dentro das Forças Armadas, sendo este um âmbito de tensões e conflitos contínuos e, como citado por Fico, "Cabia ao SNI incentivar a especialização pessoal, bem como 'promover a formação de uma correta mentalidade de informação entre os integrantes do SISNI'9 (FICO, 2001, p. 82)". Legitimador na busca de unificar e reforçar o pensamento autoritário/conservador, a partir da preocupação com a moral e os costumes, pensamento este central no projeto ideológico proposto e presente tanto no interior do aparato repressivo, como também, em parte da sociedade civil. Assim, entendemos que a função do SNI - agência São Paulo, neste momento, era a de conjugar a alimentação da informação com a ideia de formação de uma mentalidade homogênea e conservadora a todos os membros do aparato repressivo e fora dele.

${ }^{9}$ O SISNI significa Sistema Nacional de Informações. 


\title{
Costumes e Indústria Cultural
}

A produção documental contida nas 'Apostilas do Comunismo Internacional', como discutido, dirigia-se em primeira instância aos membros do aparato repressivo, responsáveis pelo controle, vigilância e repressão da sociedade, orientando, justamente, a ação destes sujeitos. Seguia-se, assim, na busca pela homogeneização e legitimação a partir do próprio Estado, através de seu aparato repressivo. Esta composição será acompanhada pela difusão da lógica da indústria cultural, fomentada neste momento. É interessante observarmos algumas características da indústria cultural no Brasil: dissemina-se com intensidade justamente nestes anos de ditadura militar e com grande fomento do Estado; a lógica da indústria cultural corrobora à aproximação geopolítica com os EUA reforçando, assim, a perseguição ao comunismo e a identificação como o inimigo nacional; por fim, contribui com a busca de legitimação, apesar de apresentar-se de modo dicotômico. Pensemos sobre estas questões.

Renato Ortiz, em seu livro seminal sobre a indústria cultural no Brasil, mostrou o necessário incentivo do Estado para o desenvolvimento de um parque industrial relacionado à produção cultural:

\begin{abstract}
na verdade o setor livreiro se beneficia de toda uma política implementada pelo governo que procura estimular a produção de papel e reduzir o seu custo. (...) Em 1960 a produção brasileira de papel off-set para livros era de $7 \%$ do total, em 1978 ela sobe para 58\%.Mas não é somente o setor livreiro que se beneficia da política governamental (ORTIZ, 1988, p. 122).
\end{abstract}

A ditadura militar brasileira instalada em 1964 com um definido projeto de desenvolvimento para o país provocou, também, a reorganização e o fortalecimento do parque industrial da produção cultural. Retomando Ortiz, vemos traduzido em números o enorme fomento à produção de bens culturais ocorrida nestes anos, como explicitado no quadro abaixo, na observação do mercado editorial, tomando a Editora Abril como exemplo. Destacamos na primeira tabela a quantidade de títulos desta editora e na segunda tabela a quantidade de exemplares em milhões, por títulos de livros, considerando-se todas as editoras:

Tabela 1

\begin{tabular}{|l|l|l|l|}
\hline Ano & $1950-59$ & $1960-69$ & $1970-79$ \\
\hline Títulos & 7 & 27 & 121 \\
\hline Fonte - ORTIZ, 1988, P. 122 & &
\end{tabular}


Tabela 2

\begin{tabular}{|l|l|l|l|l|l|}
\hline Ano & 1966 & 1974 & 1976 & 1978 & 1985 \\
\hline exemplares & 43,6 & 191,7 & 112,5 & 170,8 & 245,4 \\
\hline
\end{tabular}

Fonte: ORTIZ, 1988, P. 122

Considerando as duas tabelas, notamos um aumento em $300 \%$ na produção editorial, nos anos 1970; como discutido amplamente por Ortiz (1988) o mesmo pode ser observado em outros nichos da produção cultural, como no setor fonográfico, com o aumento das vendas dos aparelhos eletrônicos domésticos e a venda dos discos. Assim, para cada aumento da produção de bens culturais setorizados, devemos considerar o desdobramento produtivo em muitos âmbitos, como observado em relação aos mercados editorial e fonográfico. Percebemos assim, que importantes setores de produção industrial permitiram o aumento da produção e circulação de bens culturais, alçando-os à lógica massiva de circulação do bem cultural.

Entendemos que o Estado pactuou com esta lógica, como parte de seu projeto ideológico de desmontagem da hegemonia cultural de esquerda, predominante no Brasil desde os anos 1950. Isto porque o desenvolvimento da produção cultural vem acompanhado da transformação do conteúdo dos bens culturais, bem como, da modificação das formas de apropriação dos mesmos. Interessantíssima a citação de Napolitano para mostrar a complexidade da questão "Na propaganda de aparelho de som da alta tecnologia, publicada na revista Isto $\hat{E}$, em 23 de junho de 1977, lia-se a seguinte chamada: 'Para ouvir canções de protesto contra a sociedade de consumo, nada melhor do que um Gradiente financiado em 24 vezes" (NAPOLITANO, 2010, p. 389). Vemos o lado sedutor da ampliação do consumo, possibilitado pelo fomento à indústria de bens culturais, alterando tanto o conteúdo dos mesmos quanto as formas de apropriação, no caso da música, pela possibilidade, facilidade e menor custo de consumo individual. Ou seja, defendemos aqui que a lógica da indústria cultural, como projeto de Estado, possibilitou novas formas de vigilância e controle. Vigilância através da busca do controle do conteúdo circulante nas mídias massivas "Quando a TV Globo e a Tupi assinam o protocolo de autocensura em 1973, procurando controlar o conteúdo de suas programações, o que estas emissoras estão fazendo é circunscrever a vontade de se conquistar o mercado a qualquer preço..." (ORTIZ, 1988, p. 120).

O controle político visível foi o cerceamento do conteúdo circulante, em moldes parecidos ao do período da censura, como citado acima. O controle não visível se consolidou de diferentes modos, entre eles, aqui discutidos, pelo aumento da burocracia, ou dito de outro modo, da inserção de uma racionalidade técnica e de um discurso de consumo, ambos fundamentados no ideário de modernidade, moldando padrões de sociabilidade. Racionalidade técnica e lógica de consumo seriam as novas facetas da despolitização política, contribuindo para a desmontagem do pensamento de esquerda. 
A intensificação da inserção da tecnologia nas relações cotidianas veio acompanhada da disseminação de uma racionalidade técnica no padrão de funcionamento e gerenciamento das empresas, inclusive as diretamente relacionadas à produção cultural, como no caso das empresas televisivas e das empresas jornalísticas. 'Também é desta fase a preocupação de se introduzir novas normas na redação, procurando torná-la mais produtiva e eficiente..." (ORTIZ, 1988, p. 139). Na prática isto significou o começo do fim das empresas familiares e o início de um entendimento de profissionalização e eficiência, através da burocratização, calcada no binômio planejamento - execução, que teve como cerne a proposição de separação entre setores que planejam e setores que executam, o que gera a concentração do poder nas mãos de pequenos grupos, delegando às massas a execução das tarefas. Utilizaremos o setor publicitário como exemplo, mas esta dinâmica pode ser observada em diferentes áreas:

\begin{abstract}
Se a década de 60 , em nossas agências, pode ser caracterizada como a década da criatividade, com o prestígio maior concedido aos homens de criação, os anos 70, que trouxeram a valorização da agência como empresa, levariam a consolidação definitiva do negócio publicitário entre nós. $\mathrm{E}$ assim, de uma década um tanto inconsequente- a de 60 marcada pelo devaneio criativo, passaram nossas agências a saber encarar as crises com seriedade, através da profissionalização de todos os seus setores essenciais. Adotaram novas técnicas de planificação, de pesquisa, de conceituação e posicionamento de produto, de avaliação da propaganda realizada. Multiplicaram-se na mídia os instrumentos de avaliação, de análise, de planejamento, de controle. (REIS, 1990, p. 365)
\end{abstract}

O conceito de profissionalização se disseminou como sinônimo de desenvolvimento e modernidade, presente na publicidade de diferentes produtos, como nas primeiras peças publicitárias de computadores domésticos no início dos anos 1980, com o slogan "O micro para profissionais". ${ }^{10}$ No caso específico das agências de publicidade um estudo demonstra que "essas taxas de crescimento não ocorreram em nenhum outro país, mesmo os mais avançados, o que permite que em 1972 o Brasil supere países como a Itália, Holanda e Austrália, para se constituir em 1974 o sétimo mercado de propaganda do mundo" (ORTIZ, 1988, p. 131). Com o mercado publicitário em crescimento vertiginoso, temos o aumento da oferta de produtos e lógicas de consumo e, como colocado pelo mesmo autor ao diferenciar o mercado de bens materiais e bens culturais " $O$ último envolve uma dimensão simbólica que aponta para problemas ideológicos, expressam uma aspiração, um elemento político embutido no próprio produto veiculado" (ORTIZ, p. 114). Ao observarmos o mercado das agências publicitárias vemos a presença de importantes agências multinacionais, como McCann-Erikson, Thompson e Lintas e, considerando, como exemplo, o mercado editorial já citado, vemos no Brasil a publicação de revistas femininas que dialogavam com as questões

\footnotetext{
${ }^{10}$ Esta publicidade foi veiculada na revista Isto É em $07 / 02 / 84$. Sobre este tema especificamente ver a dissertação de mestrado "As origens da informatização do lar brasileiro: o caso do computador doméstico (1984-86) de Silvia Helena de Araujo Bueno.
} 
femininas e feministas do contexto pós-1968, sofrendo forte influência do debate sobre a condição feminina proposto em diferentes países, como França e EUA, ou mesmo apresentando-se como versões brasileiras de revistas internacionais, como é o caso da revista Nova, versão brasileira da Cosmopolitan. Assim, perguntamo-nos como foi articulada a proposta de consumo no confronto entre ideários conservadores e libertários, considerando as revistas femininas como objeto exemplificador. São duas ordens de tensões claramente anunciadas: moralidade conservadora frente aos ideários libertários e interesses político-econômicos dos setores de mercado, na disseminação de produtos com clara carga simbólica frente às condutas repressoras e conservadoras do Estado autoritário.

Começando pelo primeiro aspecto, diferentes trabalhos acadêmicos (dissertações e teses) ${ }^{11}$ vêm discutindo o papel das revistas femininas neste contexto, demostrando como a questão feminina trouxe em seu bojo aspectos caros ao debate moralidade- liberdade, questionando a condição da sexualidade feminina, implicando no papel do feminino na sociedade e nas configurações familiares. Uma das revistas pioneiras nesta linha foi a revista Realidade (1966) que trazia temas-dossiês em suas edições, temas estes sempre bastante polêmicos, como a edição de janeiro de 1967 com um dossiê sobre a mulher. Como podemos observar no sumário presente na capa abaixo, a edição propunha o debate sobre questões femininas, como o corpo feminino, maternidade, parto, aborto etc., questões estas que provocaram a censura temporária da revista. Em outras edições discutiu a situação do jovem, o racismo no Brasil, entre outras questões.

Figura 1 - Revista Realidade

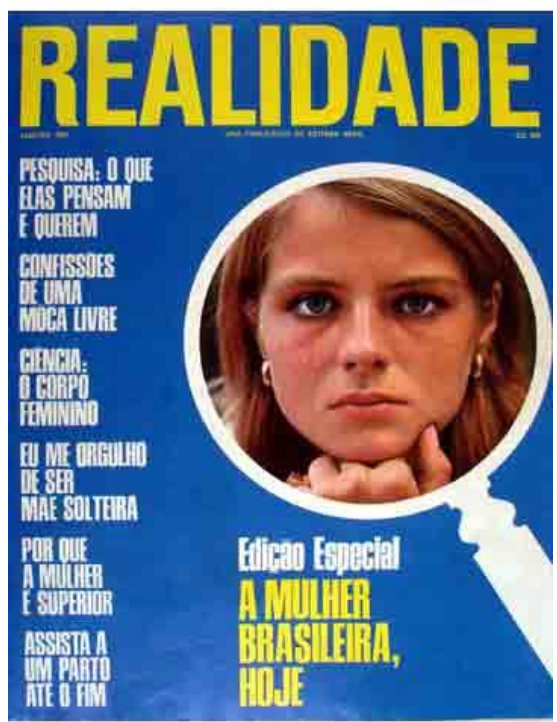

Fonte: edição n. 10, jan. de 1967

\footnotetext{
${ }^{11}$ Partimos do livro de Dulcília Buitoni, 'Mulher de Papel: a representação da mulher pela imprensa feminina brasileira' (2009) e a partir deste, inúmeros outros trabalhos foram publicados. Citamos alguns bem recentes como a Tese de Carolina Cerqueira Lôbo 'Lugar de mulher: uma cartografia da construção discursiva da liberdade nas revistas femininas' ou a Tese de Gisele B. Gellacic 'Despindo Corpos- sexualidade, emoções e novos significados do corpo feminino no Brasil entre 1961 e 1985'.
} 
Entre as principais editorias no segmento feminino, temos também a revista Claudia, de 1964. A proposta editorial desta revista é interessante para nossa reflexão pois procurava discutir a questão da mulher na dicotomia colocada, sem apresentar grandes rupturas. Assim, propunha, como contrato comunicativo, a permanência de sua condição inicial, como esposa e mãe, sugerindo um possível equilíbrio com propostas libertárias na coluna de Carmem da Silva, que discutia a condição da mulher, trazendo a reflexão sobre o direito de escolha da mulher, resvalando nas temáticas relacionadas. A revista Nova (1973) exacerbou o debate por trazer como eixo central de seus artigos a sexualidade feminina como elemento de controle da mulher. Com isto, propunha temáticas sempre calcadas nos desejos e interesses femininos. Segundo Gellacic a revista sofreu censura em algumas ocasiões:

no ano de 1974, quando o artigo 'A tirania do orgasmo' foi proibido. Depois, em 1976, os artigos 'Como despertar a sexualidade' e 'Mulheres que vivem cercadas de homossexuais'...No mesmo ano, a revista foi tirada de circulação por algumas semanas, após publicar ' $\mathrm{O}$ orgasmo masculino'. Em 1978, já no período final da ditadura militar no Brasil, a revista teria sido ameaçada a ter uma restrição de vendas para menores de dezoito anos, após publicar os artigos: 'A primeira pode não ser a melhor' e 'Amor de uma noite só'” (GELLACIC, 2014,p. 53)

Apresentando-se mais ou menos conservadoras, inevitavelmente contribuíram para a reflexão sobre as instituições tradicionais, entre elas, a família e a igreja. Além do conteúdo editorial destas revistas, devemos lembrar o importante papel da publicidade que, por um lado, sustentará as mesmas e, por outro lado, será mais um polo discursivo neste importante debate sobre moralidade e poder. Em linhas gerais, com os produtos de beleza vinham a sedução e sexualidade do corpo feminino, cada vez mais desnudo. Assim, lingerie e maiôs femininos, com a descoberta, por exemplo, da lycra, viabilizam propagandas cada vez mais sedutoras e sexualizadas, pondo à mostra os corpos femininos. $\mathrm{O}$ mesmo ocorria com diferentes produtos de higiene, como os depiladores e cremes. Se as matérias da editoria da revista poderiam sofrer censura, como mencionado acima, o mesmo não ocorria com as propagandas veiculadas, intensificando continuamente as tensões e contradições postas na lógica dicotômica da moralidade/ repressão versus liberdade/ legitimação.

Como já indicado, a veiculação destas propagandas atendia aos interesses de mercado, nem sempre completamente consoantes ao projeto político militar, criando uma clara dicotomia entre o discurso e práticas militares e o teor das propagandas, principalmente as propagandas contidas nas revistas segmentadas, em função do forte poder e impacto das imagens, como acima indicado. Isto não quer dizer, que, em princípio, havia discordâncias. Todas as agências publicitárias eram, naquele momento, regidas pelo Código de Ética dos Profissionais da Propaganda "referido no art. 17 da Lei 4.680 de 18 de junho de 1965: I- Não é permitido: a) publicar textos ou ilustrações que atentem contra a ordem pública, a moral e os bons costumes;..." e possuíam uma profunda sintonia com os governos militares em relação ao modelo econômico, ampliando a capacidade e espaço de interesse pelo consumo: 
Se tomarmos o risco de continuar uma economia em cima de uma bicicleta e paramos de pedalar, vamos ao chão. Temos de encontrar um mecanismo que amplie o repertório de bens e serviços que cada homem quer a cada instante, e que amplie de forma violenta. Não importa muito se essa ampliação cria problemas sociais. Os problemas sociais são necessários para a realização do próprio desenvolvimento. 0 importante é que cada um queira mais, cada vez mais, mais coisas. Essas palavras do prof. Antonio Delfim Neto, proferidas durante a sua aula inaugural na Escola Superior de Propaganda e Marketing de 1971, caracterizam com rara felicidade o importante papel macroeconômico que cabe à 'função propaganda' no atual contexto brasileiro. (SCHERB In Anuário Brasileiro da Propaganda, ano 1974/75, p. 18)

A nosso ver, os governos militares buscaram driblar esta questão, exercendo a censura ao conteúdo dos artigos publicados ou mesmo a edições inteiras, como foi o caso da revista Claudia de 1967, já citada, mas mostrou-se mais maleável à publicidade, criando muitas vezes uma certa dubiedade no interior das revistas, ao apresentarem conteúdos mais conservadores acompanhados de propagandas de grande teor sedutor. Aqui, o princípio do mercado prevaleceu, mercado este pautado pelo consumo despolitizado. Assim, entendemos que a negociação da lógica da repressão-legitimação ocorreu em etapas e processos, priorizando a desmontagem dos setores de esquerda e da cultura de esquerda, amplamente arraigada na cultura brasileira, deixando parte desta mesma desmontagem a cargo da disseminação de bens culturais massivos privilegiando, neste caso, a circulação de bens despolitizados e voltados para a valorização do prazer, arcando com os riscos que a lógica de consumo impunha conquanto que garantissem a desestruturação do modelo de cultura de esquerda existente até então. A publicidade e o consumo contribuíram com as transformações culturais no âmbito dos costumes, favorecendo, posteriormente, uma composição ao mesmo tempo conservadora, sem nexos éticos. Como discutem Novais e Mello, o Brasil se caracterizará por um autoritarismo conservador e pouco moral.

Historicamente, a modernidade resulta e avança por meio da tensão permanente entre o conjunto de valores mercantis, utilitários, propriamente capitalistas, e o outro conjunto de valores, fundamentados seja religiosa, seja secularmente. Mais ainda: são os valores modernos não mercantis, não capitalistas que, corporificados em instituições ( a democracia de massas, a escola republicana, as igrejas, a família cristã etc.), põem freios ao funcionamento desregulado e socialmente destrutivo do capitalismo.

É esta conjunção marcada por tensões que, como dissemos, não se configura no Brasil. Isto tem, evidentemente, profundas raízes históricas, antes de mais nada no caráter do nosso catolicismo...estamos diante de um cristianismo inteiramente esvaziado de conteúdo ético.(...)

É neste vácuo moral, nesta sociedade em que, como observou Caio Prado Jr. neste livro notável que é Formação do Brasil Contemporâneo, não há nexos éticos entre os homens, mas só relações de exploração econômica e de dominação política, nesta sociedade em que impera a 
'vontade de poder' em meio às espontaneidades dos afetos, que a razão instrumental pode penetrar com facilidade. ( NOVAIS e MELLO, 2000, p.607-608)

Não entendemos que esta composição 'conservadorismo sem moralidade' seja uma das facetas do projeto ideológico militar, mas o vemos como um dos aspectos reforçados pelas tensas e dinâmicas relações de repressão - negociação postas ao longo do regime militar.

\section{Bibliografia}

ALVES, Maria H. Moreira. Estado e Oposição no Brasil ( 1964 _ 1984), Petrópolis, Editora Vozes, 1989, p.33-37

BUENO, Silvia Helena de Araújo. As origens da informatização do lar brasileiro: o caso do computador doméstico (1984-86), Dissertação de Mestrado, Guarulhos, 2015

CHARTIER, R. “O Mundo como Representação” IN Estudos Avançados n. 11, 1991.

----. A História Cultural- entre práticas e representações, Lisboa: Difel, 1990.

..Textos , impressões e leituras IN Hunt, Lynn. A Nova História Cultural, São Paulo: Martins Fontes, 2001.

D'ARAUJO,Maria Celina, SOARES,Gláucio Ary D. e CASTRO, Celso. Os Anos de Chumbo _ A Memória Militar sobre a Repressão, R.J., Relume _ Dumará, 1994, p. 45.

BUITONI, Dulcília. Mulher de Papel: a representação da mulher pela imprensa feminina brasileira, São Paulo, Summus Editorial, 2009

FICO, Carlos. Como Eles Agiam, Rio de Janeiro, Ed. Record, 2001.

-------. “Versões e Controvérsias sobre 1964 e a ditadura militar", Revista Brasileira de História, São Paulo, v. 24, n. 47, 2004

.. Reinventando o Otimismo: ditadura, propaganda e imaginário social no Brasil (1969-1977), Tese, São Paulo, 1996

FOUCAULT, Michel. Microfisica do poder, Rio de Janeiro: Edições Graal, $7^{\text {a }}$, 1988

---... A Ordem do Discurso, São Paulo: Edições Loyola 20ª . Ed., 2010

GELLACIC, Gisele B. Despindo corpos- sexualidade, emoções e novos significados do corpo feminino no Brasil entre 1961 e 1985, Tese, São Paulo, 2014. 
LOBO, Carolina C. Lugar de Mulher: uma cartografia da construção discursiva da liberdade nas revistas femininas, Tese, São Paulo, 2015.

MARTINS FILHO, João Roberto. O Palácio e a Caserna, São Carlos, Editora EDUFSCar, 1995

NAPOLITANO, Marcos. "Vencer Satã só com orações: políticas culturais e cultura de oposição no Brasil dos anos 1970" IN ROLLEMBERG, Denise e QUADRAT,S. (orgs) A construção social dos regimes autoritários, Rio de Janeiro, Civilização Brasileira, 2011.

--... 'MPB: a trilha sonora da abertura política (1975/1982)' IN Estudos Avançados, no. 24, 2010.

NOVAIS, Fernando e MELLO, João M. C. "Capitalismo Tardio e Sociabilidade Moderna" In Novais, F. (org.) História da Vida Privada no Brasil, São Paulo, Companhia das Letras, 2000, vol. 4 .

ORTIZ, Renato. A Moderna Tradição Brasileira, São Paulo, Brasiliense,1988.

REIS, Fernando (org) História da Propaganda no Brasil, São Paulo, T. A. Editor, 1990.

REIS, Daniel A., RIDENTI, Marcelo e MOTTA, Rodrigo P. S. A Ditadura que mudou o Brasil, Rio de Janeiro, Zahar Editora, 2014.

RIDENTI, Marcelo. Brasilidade Revolucionária, São Paulo, UNESP, 2010.

\section{Fontes}

Comissão da Verdade- Relatório, vol. II, Textos Temáticos, 2014

Anuário Brasileiro da Propaganda, ano 1974/75.

Arquivo Público do Estado de São Paulo- Arquivo DEOPS:

DOSSIÊ 20.C.043 - 57 pastas; DOSSIÊ 20.C.002 -12 pastas; DOSSIÊ 21.Z.014- 148; pastas; DOSSIÊ 20.C.044- 242 pastas. 